\title{
Infección por VIH en Cuba por transmisión vertical. Reporte de nueve casos fatales en 10 años
}

\author{
Ida González N., Manuel Díaz-Jidy, Denis Berdasquera C., M. Eugenia Toledo R. y Jorge Pérez Á.
}

\section{HIV mother to child transmission. Report of nine Cuban fatal cases in ten years}

Vertical transmission of HIV infection constitutes one of the most sensitive pillars of the current pandemic of this disease. This article carries out a report of the nine Cuban children who acquired this way the infection and died between 1986 and 2006. Prophylactic management of the cases and the clinical and anatomic pathological manifestations of those in whom autopsy was performed are described. The average gestational age was of 37.6 weeks, four of the pregnancies were captured late. Six children were born by caesarean section and in all transmission were presumably intrauterine. The average birth weight was 2786 grams. Four mothersibling binomial received prophylaxis with AZT. The autopsy was carried out only in 4 children.

Key words: HIV/AIDS, pregnancy, vertical transmission, death.

Palabras clave: VIH/SIDA, embarazo, transmisión vertical, muerte.

\section{Introducción}

$\mathrm{M}$ ás de $90 \%$ de los niños infectados en el mundo con el virus de inmunodeficiencia humana (VIH) han adquirido la infección por transmisión vertical (TV), alcanzando cerca de 100\% en los países subdesarrollados. Al cierre del 2006, se estimó que 700.000 lactantes en todo el mundo habían contraído la infección por el VIH, la inmensa mayoría de ellos durante la gestación y el parto, o asociado a la lactancia materna. Cerca de 570.000 han fallecido a raíz del SIDA ${ }^{1}$.

Estudios llevados a cabo en niños infectados por TV han permitido clasificar la historia natural de la enfermedad en dos formas de presentación clínica. En la primera, los niños se presentan con manifestaciones precoces y con enfermedades graves marcadoras de SIDA en los primeros meses de vida, que puede incluir o no al SNC. La forma de progresión es rápida y abarca aproximadamente a 15 - 25\%, de los casos; antes de la era de los anti-retrovirales, fallecían entre los tres y cinco años de edad. En la segunda forma evolutiva, las manifestaciones clínicas iniciales aparecen entre los cuatro y siete años de edad, con las enfermedades oportunistas marcadoras de SIDA y el curso de la enfermedad es más lento; son los llamados progresores lentos y constituyen 75 a $85 \%$ de los niños. Antes de la era de los anti-retrovirales fallecían al entrar en la adolescencia y su evolución es similar a los adultos aunque con una velocidad mayor que la observada en ellos ${ }^{2-4}$. La velocidad de progresión de la infección hasta llegar a desarrollarse el SIDA estaría determinada por múltiples factores, a saber: momento de la transmisión: in útero o intraparto, estado inmunitario materno (recuento de CD4) y carga viral (CV) materna durante la gestación, estado inmunitario del RN, factores genéticos del hospedero y otros inherentes a la cepa viral, en investigación. Favorecerían una forma de progresión rápida la infección por VIH transmitida in útero, un recuento de CD4 bajo y CV viral materna alta durante el embarazo y una carga viral alta y recuento bajo de CD4 en el niño en las primeras semanas de vida-9.

En Cuba, el Programa de Prevención y Control del VIH/SIDA ${ }^{10}$, ha ido incorporando diversas medidas profilácticas para la transmisión vertical en la medida de haberse establecido su utilidad, las que se resumen así: proscripción de la lactancia materna reglamentada desde 1986, resolución del parto por cesárea programada al termino del embarazo desde 1989, profilaxis con zidovudina (AZT) desde 1997, administración de tratamiento anti-retroviral de gran actividad (TARGA) a aquellas mujeres gestantes que tengan $\mathrm{CV}$ mayor de 1.000 copias de ARN/ml y CD4 menor de 350 células/ $\mathrm{mm}^{3}$, en un primer chequeo realizado al iniciar el control del embarazo, desde el año 2001. Además, partir de 2003 se incluyó la realización de una segunda prueba de ELISA para VIH en el segundo trimestre de la gestación, RPC para VIH en papel de filtro a todos los hijos de madres seropositivas desde el año 2004 y la admi-
Instituto de Medicina Tropical Pedro Kourí, La Habana, Cuba.

Recibido: 18 de mayo 2007 Aceptado: 28 de noviembre de 2007

Los autores declaran no tener conflictos de intereses.

Correspondencia a: Ida González Núñez jidy@ipk.sld.cu Denis Berdasquera Corcho denis@ipk.sld.cu 
nistración de AZT endovenoso intraparto en las cesáreas programadas a todas las mujeres gestantes portadoras del virus, desde el año 2005. El cumplimiento de estas normativas ha permitido que, hasta el 31 de diciembre de 2006, se hayan pesquisado 265 niños hijos de madres seropositivas: 124 del sexo femenino y 141 masculinos. Esta cifra incluye todos los niños nacidos bajo esta condición, independientemente de que la madre haya recibido o no TARGA. De ellos, 29 han sido infectados, 27 han desarrollado SIDA - 9 han fallecido y 18 reciben TARGA, dos son asintomáticos. Del resto de los niños; 172 resultaron no infectados por el VIH, demostrado por dos RPC y dos Western blot negativos entre los 18 y 24 meses de edad y, al momento de realizarse este reporte, 64 se encuentran en estudio. La tasa de transmisión general madre-hijo, al cierre de 2006, fue de $10,9 \%$ (29/265) y de 3,2\% (1/29) en aquellas madres que cumplieron correctamente todas las medidas profilácticas indicadas en el programa de prevención y control implantado en el país.

En el presente artículo se presentan todos los niños que adquirieron la infección por VIH/SIDA por TV en Cuba y fallecieron, sus aspectos clínicos y evolutivos, los hallazgos anátomo-patológicos de aquellos a los que se les realizó necropsia y el análisis de cumplimiento de las medidas profilácticas en ellos.

\section{Pacientes y Método}

Estudio descriptivo, retrospectivo, de los 9 niños infectados por VIH/SIDA por vía vertical, fallecidos en Cuba entre el $1^{\circ}$ de enero de 1986 y el 31 de diciembre de 2006. Los datos se obtuvieron de las historias clínicas de los pacientes registrados en el Departamento de Archivos del Instituto de Medicina Tropical Pedro Kourí (IPK), (centro nacional de referencia para la asistencia médica de estos pacientes, donde se efectúan los exámenes de todo el país, y se ejecuta el protocolo de seguimiento de todos los hijos de madres seropositivas para VIH), de la base de datos de seguimiento de los mismos y de los registros de laboratorio clínico de la institución.

La información recopilada se presenta analizando cada caso por separado y en orden cronológico según fecha de nacimiento y fallecimiento, resumidos en dos tablas finales. En la primera se recoge información sobre las condiciones de embarazo, medidas preventivas utilizadas, tipo de parto, profilaxis con AZT aplicada a la madre y al niño, así como peso al nacer del niño. En la segunda, se refleja la distribución de los fallecidos según edad al diagnóstico de infección por VIH, recuento de $\mathrm{CD}_{4}$ (y CV a los que se les realizó), enfermedades oportunistas, edad al fallecimiento y, en los que los padres autorizaron efectuar la necropsia, se refleja la causa directa, indirecta y básica de la muerte.

Para la clasificación del paciente según lo normado por el CDC de Atlanta se empleó dos categorizaciones, la de $1987^{11}$, que se aplicó a los niños nacidos hasta 1996 teniendo en cuenta sólo el estado clínico e infecciones experimentadas, pues en Cuba no se contaba, hasta esa fecha, con el citómetro de flujo para realizar sub-población linfocitaria (CD3, CD4, y CD8), y la de $1994^{12}$, utilizada a partir de entonces, en la que se reclasificaron los niños vivos y los nuevos nacimientos teniendo en cuenta el estado clínico e inmunológico del niño. Se analizan frecuencias absolutas y se compararon proporciones.

\section{Resultados}

El 44,4\% (4/9) de los embarazos fueron pesquisados después de las 14 semanas de gestación.

La edad gestacional media de las madres, al momento del parto, fue de 37,6 semanas (Tabla 1).

Seis niños 66,6\% (6/9) nacieron por cesárea, el peso promedio al nacer fue de 2.786 gr. Cuatro binomios madre-hijo (44,4\%) recibieron profilaxis con AZT.

Todos los infantes de nuestra casuística desarrollaron una progresión rápida hacia el SIDA en los primeros meses y años de la vida y en dos casos se presentó compromiso del SNC.

Seis de los niños $66,6 \%$ presentaron neumonía por Pneumocystis jiroveci.

Cinco (55,5\%) de los nueve fallecidos eran lactantes bajo un año de edad, siete fallecieron antes de arribar al segundo año $\mathrm{y}$, de forma general, ocho murieron antes de los cinco años de edad.

Se efectuó necropsia a cuatro de los fallecidos $(44,4 \%)$. La causa básica de la muerte en todos los casos fue el SIDA y en los que se les realizó necropsia, las principales causas directa de la muerte fueron: hipertensión endocraneana (n: 1), cor pulmonar crónico (n: 1), insuficiencia respiratoria por citomegalovirus (n:1), neumonía mixta por $P$. jiroveci y CMV (n:1).

Caso 1: Paciente femenina, nacida en 1986, en Ciudad Habana, a las 39 semanas de gestación, hija de ambos padres seropositivos para VIH. Fue el primer caso que se diagnosticó en el país en 1986, al comienzo de la implementación del programa de prevención y control. Se inició en control del embarazo en la madre a las 20,1 semanas de gestación. Nació por vía vaginal. Ni la madre ni la niña recibieron tratamiento con ARV, pues no fue hasta 1997 y 2001, que estas medidas se incorporaron al programa respectivamente. Falleció en 1990 a la edad de 3 años 3 meses. Experimentó el primer 


\begin{tabular}{|c|c|c|c|c|c|c|c|c|c|}
\hline $\begin{array}{l}\text { Antecedentes } \\
\text { clínicos }\end{array}$ & 1 & 2 & 3 & 4 & $\begin{array}{c}\text { Casos } \\
5\end{array}$ & 6 & 7 & 8 & 9 \\
\hline $\begin{array}{l}\text { Detección del } \\
\text { embarazo }\end{array}$ & 20,1 semanas & 12 semanas & 16 semanas & 11 semanas & 10 semanas & 18 semanas & 12 semanas & 20 semanas & 11 semanas \\
\hline Tipo de parto & Vaginal & Cesárea & Vaginal & Cesárea & Cesárea & Cesárea & Cesárea & Vaginal & Cesárea \\
\hline $\begin{array}{l}\text { Edad gestacional al } \\
\text { parto }\end{array}$ & 39 semanas & 39 semanas & $\begin{array}{l}38 \text { semanas } \\
+3 \text { días }\end{array}$ & $\begin{array}{l}38 \text { semanas } \\
+4 \text { días }\end{array}$ & $\begin{array}{l}33 \text { semanas } \\
+6 \text { días }\end{array}$ & $\begin{array}{l}38 \text { semanas } \\
+5 \text { días }\end{array}$ & 40 semanas & 35 semanas & 37 semanas \\
\hline $\begin{array}{l}\text { Peso al nacer } \\
\text { en gramos }\end{array}$ & $3.500 \mathrm{gr}$ & $2.900 \mathrm{gr}$ & $2.850 \mathrm{gr}$ & $3.175 \mathrm{gr}$ & $1.940 \mathrm{gr}$ & $3.540 \mathrm{gr}$ & $2.750 \mathrm{gr}$ & $1.870 \mathrm{gr}$ & $2.550 \mathrm{gr}$ \\
\hline $\begin{array}{l}\text { Profilaxis con AZT } \\
\text { en la madre }\end{array}$ & No & No & No & No & Sí & Sí & Sí & No & Sí \\
\hline $\begin{array}{l}\text { Profilaxis con AZT } \\
\text { en el niño }\end{array}$ & No & No & No & No & Sí & Sí & Sí & No & Sí \\
\hline
\end{tabular}

patrón evolutivo (progresión rápida), necesitando ingresos hospitalarios en 14 oportunidades, con múltiples enfermedades oportunistas como muestra la Tabla 2. Según la clasificación del CDC de Atlanta de 1987, se ubicó en el grupo P-2 ABCDF. Se le realizó necropsia y la causa directa de la muerte fue una hipertensión endocraneana secundaria a encefalitis de curso sub-agudo.

Caso 2: Paciente femenina, nacida en 1989, en Ciudad Habana, a las 39 semanas de gestación, hija de ambos padres seropositivos para VIH. Se captó el embarazo de la madre a las 12 semanas de gestación. $\mathrm{Ni}$ la niña ni la madre recibieron profilaxis con AZT. Nació por cesárea programada y desarrolló una progresión rápida de enfermedad. Tuvo ocho ingresos hospitalarios por múltiples enfermedades oportunistas, como neumonía por $P$. jiroveci (marcadora de SIDA) y otras patologías (Tabla 2). Según la clasificación del CDC de Atlanta de 1987 se ubicó en el grupo P-2 ACDF. Falleció en 1991, a la edad de 1 año 11 meses. Se le realizó necropsia estableciéndose como causa directa de la muerte cor pulmonar crónico (secundario a daño pulmonar) descompensado.

Caso 3: Paciente masculino, nació en 1995 a las 38 semanas y cinco días de gestación. Hijo de ambos padres seropositivos para VIH. El diagnóstico de SIDA fue efectuado post-mortem. Nació por vía vaginal en Manzanillo, provincia Granma. La madre ocultó su condición de infección por VIH y la captación de su caso ocurrió a las 16 semanas de gestación. Se trasladó a Ciudad Habana con el niño de 4 meses de edad e ingresó en el Servicio de Terapia Intensiva del hospital pediátrico Centro Habana, con compromiso del estado general, dificultad respiratoria grave, acompañado de candidiasis oral, diarrea y desnutrición, configurando un cuadro clínico muy sugerente de infección por VIH/ SIDA, por lo que se buscó y confirmó el diagnóstico por el laboratorio. Clasificó en el patrón evolutivo de progresión rápida con enfermedades oportunistas como neumonía por $P$. jiroveci. (Tabla 2). Falleció en octubre de 1995, a la edad de 4 meses 3 días. Se ubicó según la clasificación del CDC de Atlanta de 1987 en el grupo P-2 ACDF. El diagnóstico confirmatorio por RPC fue recibido después de su fallecimiento. Se le realizó necropsia donde se constató la co-existencia de una neumonía extensa por citomegalovirus (CMV) y $P$. jiroveci y una enterocolitis necrosante ulcerativa. (Figuras 1 y 2).

Caso 4: Paciente masculino, nacido en 1993, en Santi-Spiritus, a las 38 semanas y cuatro días de gestación, hijo de ambos padres seropositivos para VIH. El embarazo de la madre se detectó a las 11 semanas de gestación. Ni el niño ni la madre recibieron profilaxis con AZT. Nació por cesárea programada. Contrajo múltiples infecciones oportunistas (Tabla 2). La madre falleció cuando el paciente tenía 2 años 10 meses. Desarrolló un patrón evolutivo de progresión rápida experimentando 12 ingresos hospitalarios. Recibió monoterapia desde 1995 con AZT, biterapia en 1996 con AZT + ddI, en 1997 cambió a 3TC + SQV, en el 2000 a NVP + APV y, a partir del año 2001 inició TARGA con distintos esquemas: NVP + APV + EFV y NVP + APV + Lpv/rtv, por desarrollar resistencia a la mayoría de los ARV indicados. Clasificó según criterios del CDC de Atlanta de 1987 en el grupo P-2 ACDF y en 1996 fue reubicado en el grupo C-3 según la clasificación de 1994. 
Tabla 2. Distribución de niños con VIH/SIDA adquirido por transmisión vertical fallecidos, según edad al diagnóstico de infección, recuento de $\mathrm{CD}_{4}$, carga viral, infecciones oportunistas, edad al fallecimiento y causa de muerte. Cuba 1986-2006

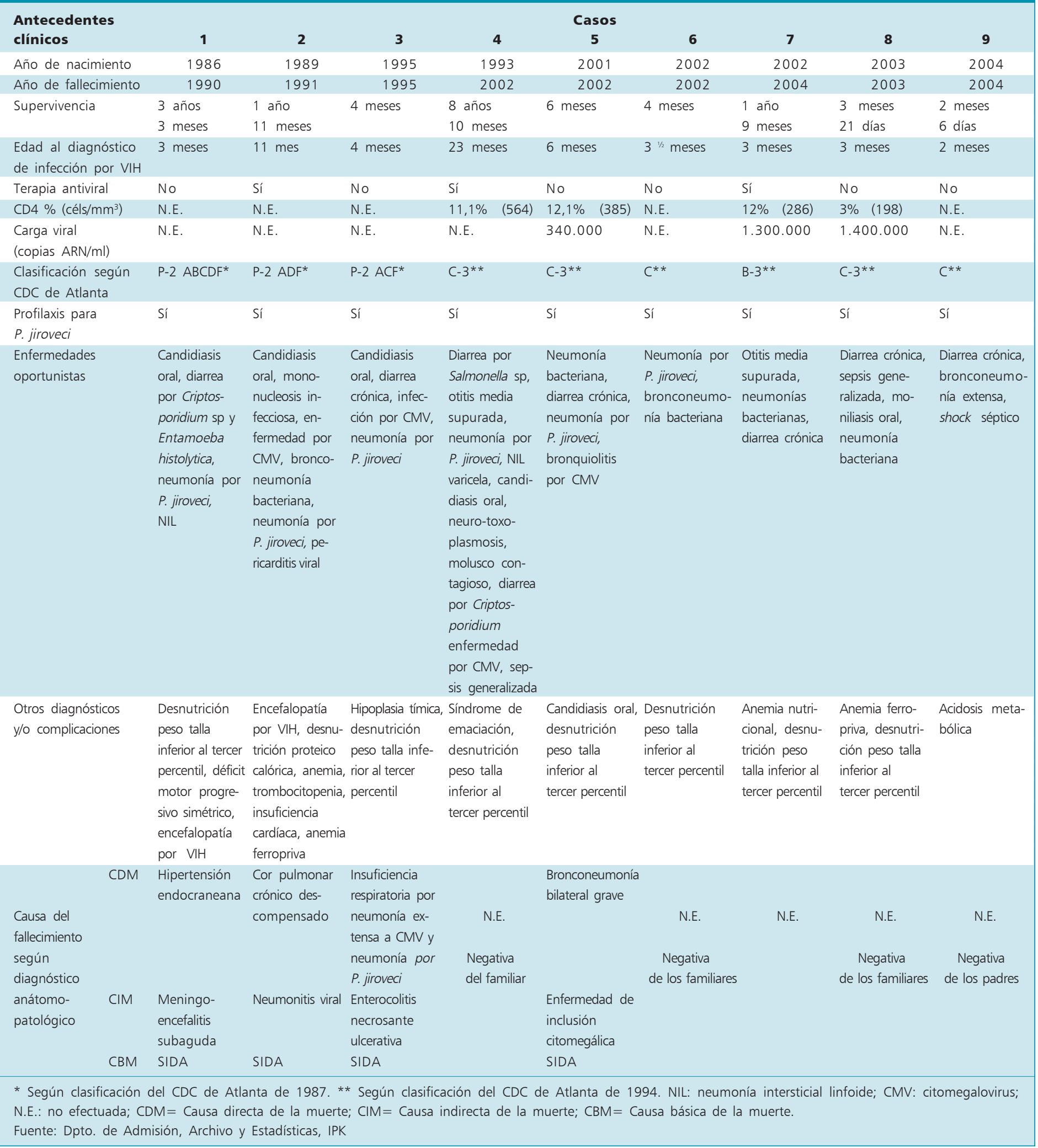


Falleció en 2002, a la edad de 8 años 10 meses, con síndrome de emaciación. No se le realizó necropsia por negativa de los familiares.

Caso 5: Paciente masculino, nacido en el año 2001, en Cienfuegos a las 33 semanas y seis días de gestación. Parto de pretérmino, vía cesárea, por ser ambos padres seropositivos para VIH. Pesó al nacer 1.940 gramos. Se captó el embarazo de la madre a las 10 semanas de gestación y con 14 semanas se le indicó AZT, pero se comprobó mala adherencia al tratamiento profiláctico. El niño recibió AZT durante las primeras 6 semanas de vida. Estuvo internado en el Servicio de Neonatología de su hospital provincial hasta que recuperó peso. Se comprobó en el interrogatorio un mal manejo por parte de la madre en cuanto al prepararle los alimentos al niño. A partir de los 3 meses de vida, fue internado en el hospital, en dos ocasiones, por diarreas y vómitos. A los $3 \frac{1}{2} 2$ meses se internó, por neumonía, en su provincia y a los 4 meses de edad fue traído al IPK para realizarle el chequeo de pesquisa del VIH. Llamó la atención que la RPC fuera negativa, pues el niño continuaba con un cuadro respiratorio compatible con neumonía por $P$. jiroveci, acompañado de síntomas generales característicos de SIDA (adenopatías cervicales, axilares e inguinales, hepato-esplenomegalia, desnutrición, aumento de volumen en las parótidas, anemia, candidiasis oral y otros) (Tabla 2). Se le repitió una RPC para VIH cuyo resultado fue positivo. Se inició tratamiento para $P$. jiroveci y TARGA (ABC + 3TC + RTV). Tenía CV de 340.000 copias ARN/ml y CD4: 12,1\%. Se clasificó en el grupo $\mathrm{C}-3$. Internado por quinta vez en su provincia, con 5 1/2 meses de edad, se derivó a especialistas en el IPK, ya que el niño no tenía una mejoría evidente y se corroboró que la adherencia a TARV era insuficiente. Presentaba un cuadro respiratorio grave, diarrea crónica por CMV y el resto de la sintomatología ya señalada. Se trasladó a la sala de terapia intensiva, falleciendo en abril de 2002, a la edad de 6 meses 14 días. Se le realizó necropsia y se informó una bronconeumonía bilateral grave concomitante con $P$. jiroveci como causa directa de la muerte (Figura 3) y enfermedad por inclusión citomegálica intestinal como causa indirecta.

Caso 6: Paciente femenina, nacida en 2002, en Santiago de Cuba, hija de madre seropositiva para VIH y padre seronegativo. La madre fue captada con 18 semanas de gestación y se confirmó su condición de seropositiva al VIH a las 20 semanas, momento en el que inició profilaxis con AZT. La niña nació por cesárea programada a las 38 semanas y cinco días de gestación. Pesó al nacer 3.540 gramos. Recibió tratamiento con AZT oral las primeras seis semanas de vida. A los dos meses de edad ingresó en el hospital pediátrico de su provincia por síndrome febril, ligera ictericia y des-

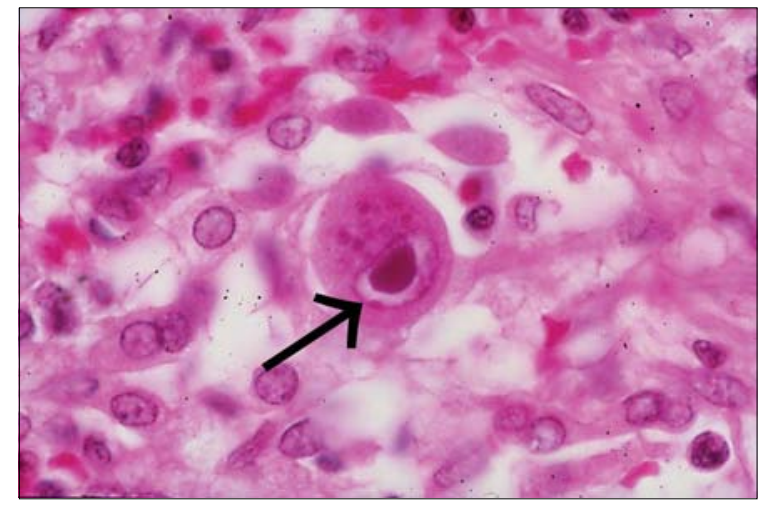

Figura 1. Inclusión citomegálica en tejido pulmonar. Tinción hematoxilina y eosina.

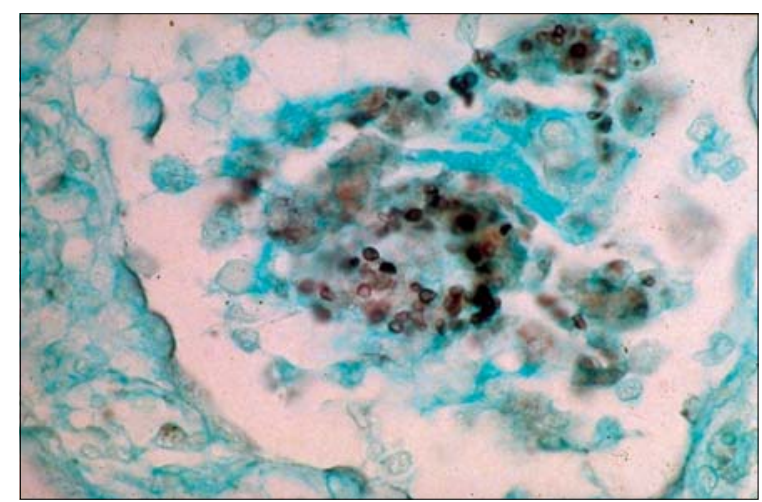

Figura 2. Imagen de quistes y trofozoitos de Pneumocystis jiroveci en tejido pulmonar. Tinción de Gromori Grocott.

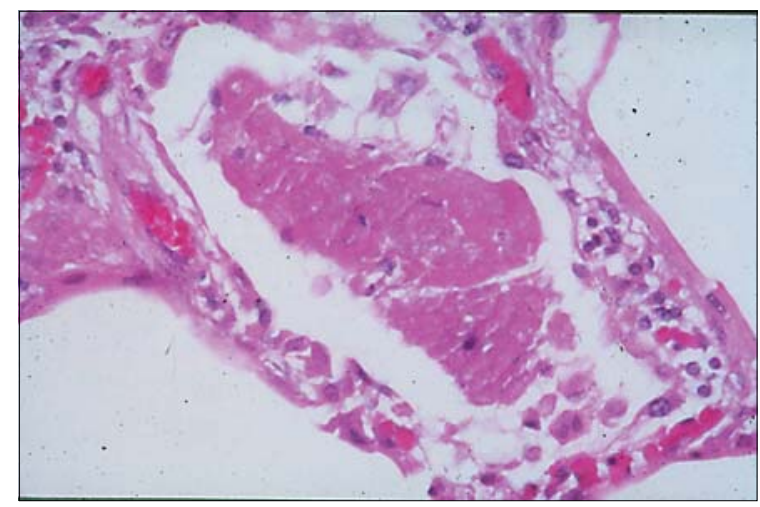

Figura 3. Se aprecia infiltrado inflamatorio pulmonar causado por Pneumocystis jiroveci. Tinción hematoxilina y eosina.

nutrición. A los $2 \frac{1}{2} 2$ meses de edad se derivó en interconsulta al IPK para su chequeo. Estuvo internada 15 días, la ictericia y la fiebre desaparecieron, observándose aumento de peso; sólo se le constató anemia nutricional. El resultado de una RPC positiva para VIH fue conocido tardíamente por su equipo tratante. La niña fue dada de alta en condiciones de "mejorada". 
Dos días después del alta presentó un cuadro de dificultad respiratoria grave siendo internada en la Unidad de Cuidados Intensivos. En la Rx de tórax se constató una bronconeumonía intersticial grave, que impresionaba como infección por $P$. jiroveci, con gran disnea y altos valores en suero de deshidrogenasa láctica. Falleció a las 24 horas de su ingreso, en diciembre de 2002, a la edad de 4 meses. Se clasificó en el grupo C. No se le llegó a realizar CD4 ni CV, tampoco. El caso fue concluido como causa directa de la muerte con el diagnóstico clínico de: bronconeumonía grave por $P$. jiroveci.

Caso 7: Paciente masculino, nacido en el año 2002, en Guantánamo, hijo de una madre seropositiva para VIH y padre sano. A la madre se le detectó precozmente el embarazo con 12 semanas de gestación, pero el resultado de la serología para VIH se conoció a las 20 semanas, momento en el que comenzó tratamiento profiláctico con AZT. El niño nació, por cesárea programada, a las 40 semanas de gestación. Pesó al nacer 3.100 gramos. Recibió profilaxis con AZT oral durante las primeras seis semanas de vida. Se trasladó a Ciudad Habana, al mes y medio de edad para su captación y seguimiento en consulta especializada del IPK. A los $21 / 2$ meses presentó una otitis media supurada. A la edad de 3 meses se recibieron los resultados de una RPC positiva para VIH y cifras disminuidas de hemoglobina. A los 6 meses de edad acudió a consulta especializada del IPK con síndrome febril, acompañado de diarrea, adenopatías cervicales, axilares e inguinales, hepato-esplenomegalia, aumento de volumen en las parótidas, candidiasis oral y en la Rx de tórax presentaba un infiltrado inflamatorio paracardíaco derecho y de ambas bases. Por el compromiso del estado general fue ingresado. Se constató una CV de 1.300.000 copias ARN/ml y CD4 de 12\%. Clasificó como SIDA en el grupo B-3 y comenzó con TARGA: AZT + 3TC + RTV Mejoró clínica e inmunológicamente -los CD4 aumentaron a 18\%- pero, posteriormente, comenzó con cuadros diarreicos frecuentes y en una ocasión, presentó una neumonía del hemitórax izquierdo, requiriendo hospitalización en tres oportunidades. Se comprobó que no tenía buena adherencia al tratamiento por olvido de la madre. En su último ingreso arribó al hospital en estado crítico, con falla respiratoria, fiebre y en la $\mathrm{Rx}$ de tórax se constató una extensa bronconeumonía bilateral. Internado en terapia intensiva, necesitó ventilación asistida, no respondió al tratamiento indicado y falleció a las 10 horas de su ingreso, a la edad de 1 año 9 meses. Los padres no autorizaron realizarle necropsia. Se concluyó el caso con los diagnósticos clínicos de SIDA, bronconeumonía bilateral grave y falla multiorgánica.

Caso 8: Paciente femenina, nacida en el año 2003 en
Cienfuegos, hija de ambos padres seropositivos para VIH. La niña fue llevada en consulta al IPK a los tres meses de edad desde su provincia donde estaba internada y abandonada por la madre. Había nacido a las 35 semanas de gestación, vía vaginal. El embarazo materno había sido captado por el médico de atención primaria a las 20 semanas, siendo una paciente indisciplinada, pues se mudó de provincia y no se controló su embarazo. Se certificó la infección materna por VIH después de nacida la niña; en consecuencia, ni la madre ni su hija recibieron tratamiento profiláctico con AZT. Al mes de nacida ingresó en terapia intensiva del hospital pediátrico de su provincia, por sepsis grave con vómitos, diarrea y deshidratación. Se le inicio tratamiento con ceftriaxona ev y medidas de sostén. Egresó tras 15 días de hospitalización. Reingresó una semana más tarde con un similar cuadro, al que se añadió una candidiasis oral, neumonía del lóbulo superior derecho, ictericia de piel y mucosas y manifestaciones compatibles con una coagulación intravascular diseminada. Se inició hidratación parenteral, infusión de eritrocitos lavados, plasma, plaquetas, vancomicina y amikacina, mejorando clínicamente pero mantuvo una ictericia verdínica. A la edad de tres meses fue referida al IPK donde se diagnosticó el SIDA; tenía CD4 en 3\% y CV de 1.400 .000 copias/ml. Fue clasificada en el grupo C-3 del CDC y se le indicó TARGA (3TC $+\mathrm{d} 4 \mathrm{~T}+\mathrm{RTV})$, que finalmente no se le administró por el agravamiento clínico de la paciente. Dos días más tarde llegó la confirmación por RPC de la infección por VIH. Falleció a la edad de 3 meses 21 días. No se le realizó necropsia. Se concluyó el caso con los diagnósticos clínicos de: SIDA, desnutrición grave y sepsis generalizada.

Caso 9: Paciente femenina, nacida en junio de 2004 en Ciudad Habana, hija de ambos padres seropositivos para VIH. La madre se embarazó a los 10 meses del parto anterior, cuyo hijo, después de ser estudiado, resultó no tener la infección por VIH. En esa ocasión se realizó consejería con ambos padres pues no era el momento oportuno para un nuevo embarazo por el deterioro clínico e inmunológico de la madre pero la pareja decidió tener el segundo hijo. Se inició el control de su embarazo a las 11 semanas de gestación y se le reinició tratamiento con TARGA que llevaba la madre, a partir de las 14 semanas de gestación con: AZT + 3TC + RTV. A las 37 semanas de gestación se resolvió el parto por operación cesárea. La RN recibió AZT durante las primeras seis semanas de vida. Fue traída al IPK a los 19 días de edad con buen estado general y buena ganancia de peso. Se orientó a la madre y se le citó dentro de 15 días pero no acudió al control. A los dos meses de edad, la paciente ingresó al hospital en estado crítico, con vómitos, diarrea, deshidratación, 
cianosis distal y disnea intensa. Se detectó acidosis metabólica y bronconeumonía extensa siendo internada en el servicio de terapia intensiva para ventilación asistida. El médico de familia de su área de salud informó que a la niña no le realizó RPC para VIH en papel de filtro, confirmatoria del diagnóstico como había sido indicado al nacer, por negativa de los padres pero, estando hospitalizada se le hizo RPC en sangre total y se documentó la infección por VIH. La evolución fue tórpida y falleció a las 72 horas de su ingreso no dando tiempo a realizar CD4 ni CV. Los padres se negaron a realizar la necropsia. Se concluyó el caso con los diagnósticos de: SIDA, bronconeumonía extensa y shock séptico.

\section{Discusión}

Este estudio incluye a todos los niños cubanos infectados por vía vertical con VIH, atendidos en el IPK y que fallecieron, en el plazo de 10 años, hasta fines del 2006. El relato cronológico de los 9 pacientes de curso fatal pone en evidencia los cambios que ha habido en el país en la atención de las mujeres gestantes seropositivas y de sus hijos expuestos a la infección desde la detección del primer caso hasta la actualidad, como se señaló en la introducción. Habría resultado del máximo interés que todos los casos fatales hubiesen tenido una examen anátomo-patológico y que a todos se les hubiese podido realizar recuento de CD4 y $\mathrm{CV}$. No obstante, en aquellos pacientes en los que no se realizó la necropsia, se pudo establecer un diagnóstico final por las características floridas del cuadro clínico altamente sugerentes de enfermedades oportunistas en el curso de SIDA.

En la literatura científica internacional se ha comunicado que, al menos una cuarta parte de los neonatos infectados por el VIH que fallecen, lo hacen antes de cumplir el primer año de vida, y alrededor de 60\%, antes de cumplir los dos años. En general, la mayoría mueren antes de los cinco años de vida ${ }^{13}$.

Los nueve pacientes fallecidos de nuestra casuística adquirieron presuntamente la infección intraútero; todos desarrollaron el patrón evolutivo de progresión rápida comenzando con sintomatología clínica precoz y enfermedades oportunistas marcadoras de SIDA que los llevaron a la muerte. Seis de los nueve pacientes presentaron la neumonía por $P$. jiroveci y otras patologías como se describen en la Tabla 2. Sólo un niño arribó a los ocho años, debido a la terapia anti-retroviral que se le suministró.

Estudios realizados han demostrado que la mediana de supervivencia, en lactantes con SIDA, no tratados con anti-retrovirales, es hasta los 96 meses de edad ${ }^{14-16}$, observándose un progresivo deterioro inmunológico precoz $^{17-20}$. Después de la aplicación del TARGA en Cuba con los esquemas descritos en la presentación de cada caso desde julio de 2002, la supervivencia ha cambiado para los niños infectados con el VIH/SIDA. De los niños vivos hasta la fecha, a 40,0\% de ellos se les ha podido prolongar la vida por encima de los cinco años de edad. Dentro de estos, tres pacientes tienen sobre 15 años de edad y cinco tienen entre seis y 14 años.

Se describe que la media de supervivencia sin tratamiento es de aproximadamente 8 a 9,5 años ${ }^{2,4}$. Aunque una pequeña proporción de niños tiene una evolución muy lenta, la mayor parte de los supervivientes con infección por vía vertical que han llegado a la adolescencia, lo han hecho con enfermedad avanzada y criterios de SIDA $^{21}$. Aproximadamente 5\% de los niños definidos como no progresores o progresores lentos alcanzan la adolescencia asintomáticos y con leve disfunción inmunológica ${ }^{2}$.

La historia natural de la infección pediátrica por VIH difiere considerablemente de la del adulto no sólo por su mayor rapidez en la evolución, sino por muchos otros aspectos ${ }^{22}$. Las infecciones predominantes son muy diferentes, en el niño las enfermedades oportunistas son primoinfecciones (por ejemplo: P. jiroveci y CMV), mientras que en el adulto son re-infecciones. En el adulto, la infección por VIH se produce en un sistema inmune hasta entonces competente, mientras que en el niño, la infección es anterior al desarrollo completo del sistema inmunológico. Además, el adulto ha tenido tiempo, en los años previos a la infección por VIH, de enfrentarse a una gran variedad de patógenos oportunistas, que en su mayoría no se han manifestado clínicamente debido a la inmunocompetencia en el momento de la adquisición del microorganismo, sobreviniendo posteriormente las manifestaciones clínicas asociada a los mismos, en la medida en que avanza la inmunosupresión. En el niño, ya inmunodeprimido desde el nacimiento, el primer enfrentamiento con un patógeno es más proclive a manifestarse clínicamente ${ }^{22}$.

En la medida en que se prolonga la supervivencia y continúa la inmunosupresión, es posible que ocurran infecciones oportunistas y éstas sean sintomáticas. El hecho de que en el niño las infecciones oportunistas sean habitualmente primoinfecciones y no reactivaciones explica, en cierta medida, que no exista un paralelismo tan estrecho entre el momento de presentación de éstas y la cifra de linfocitos CD4 ${ }^{22}$.

La infección por VIH en el paciente pediátrico es una enfermedad multi-sistémica con afectación simultánea de órganos y sistemas. Las manifestaciones clínicas iniciales suelen ser adenopatías generalizadas, hepato-esplenomegalia, parotiditis crónica, candidiasis 
oral, retraso en el crecimiento, aunque a veces el comienzo puede ser con alguna de las enfermedades indicadoras o marcadoras de SIDA $^{23}$.

En Cuba, con la implementación del Programa Nacional de Prevención del VIH/SIDA se ha optimizado el control de esta enfermedad en niños. Hoy en día se lleva a cabo una estricta vigilancia de estos pacientes y anualmente se incorporan al programa elementos encaminados a disminuir la transmisión vertical. No obstante, en ocasiones se presentan dificultades en la captación oportuna de la mujer embarazada debido a retraso en la entrega de los resultados de las serologías para VIH de las mujeres gestantes a sus consultorios, a la mala adherencia al tratamiento por parte de la madre, embarazos ocultos en adolescentes, factores que interfieren en un buen resultado del programa de control de la TV.

Este estudio muestra que la TV del VIH en Cuba tiene una baja tasa de incidencia asociado con las medidas del Programa Nacional de Prevención y Control del VIH/ SIDA y el seguimiento de la gestante seropositiva para VIH y el niño hasta el diagnóstico definitivo.

\section{Referencias}

1.- AIDS Epidemic Update. Geneva: UNAIDS;2006. Disponible en: http:// www.unaids.org/en/HIV_data/epi2006/ (Accedido: 4 de mayo de 2007).

2.- González I, Jidy M, Pérez J. Vertical transmission in Cuba. MEDICC Review 2006; 8(1). Disponible en: http:// www.medicc.org/publications/medicc_review/ 0406/cuban-medical-literature.html (Accedido: 16 de mayo de 2007).

3.- Barnhart H X, Caldwell M B, Thomas P, Mascola L, Ortiz I, Hsu H W, et al. Natural history of human immunodeficiency virus disease in perinatally infected children: an analysis from the Pediatric Spectrum of Disease Project. Pediatrics 1996; 97: 710-6.

4.- Siciliano L, López M G, Espósito A, Hernández E, Morillo L, Miranda M, et al. Evolución de pacientes pediátricos con infección vertical por el virus de la inmunodeficiencia humana. Disponible en: http://www.svinfectologia.org/vihevolu.pdf (Accedido: 16 de mayo de 2007).

5.- Mayaux M J, Burgard M, Teglas J P, Cottalorda J, Krivine A, et al. Neonatal characteristics in rapidly progressive perinatally acquired HIV 1 disease. The French Pediatric HIV Infection Study Group. JAMA 1996; 275: 606-10.

6.- Rouzioux C, Burgard M, Chaix M L, Delamare C, Cirau N, Boullier B, et al. Human immunodeficiency virus-1 infection in neonates: correlation of plasma and cellular viremia and clinical outcome. French Pediatric Cohort Srudy Group. Acta Paediatr Suppl 1997; 421: 17-21.

7.- Shearer W T, Quinn T C, Larissa P, Lew J F,
Mofenson L, Almy S, et al. Viral load and disease progression in infants infected with human immunodeficiency virus type 1 . Women and Infants Transmission Study Group. N Engl J Med 1997; 336: 1337-42.

8.- Rich K C, Fowler M G, Mofenson L M, Abboud R, Pit J, Díaz C, et al. Maternal and infant factors predicting disease progression in human immunodeficiency virus type 1 infected infants. Pediatrics 2000; 105; e8.

9.- Ioannidis J P, Tatsioni A, Abrams E J, Bulterys M, Coombs R W, Goedert J J, et al. Maternal viral load and rate of disease progression among vertically HIV-1 infected children: an international meta-analysis. AIDS 2004; 18: 99-108.

10.- Cuba. Ministerio de Salud Pública. Plan estratégico nacional ITS/VIH/SIDA, 20012006. La Habana: MINSAP; 1997.

11.- Centers for Diseases Control and Prevention. Revision of the surveillance case definition for acquired immunodeficiency syndrome. MMWR Morbid Mortal Wkly Rep 1987; 36 (Suppl 15):15-135.

12.- Centers for Diseases Control and Prevention. 1993 revised classification system for human immunodeficiency virus infection in children less than 13 years of age. MMWR Morbid Mortal Wkly Rep 1994; 43(RR-12): 1-15.

13.- Dabis F, Ekpini E R. HIV-1/AIDS and maternal and child health in Africa. Lancet 2002; 359: 2097-104.

14.- Bulterys M, Fowler M G. Prevention of HIV infection in children. Pediatr Clin North Am 2000; 47: 241-60.

15.- Scarlatti G. Pediatric HIV infection. Lancet 1996; 348: 863-8.
16.- Tovo P A, De Martino M, Gabiano C, and the Italian Register for HIV infection in children. Prognostic factors and survival in children with human immunodeficiency virus type-1 infection. Lancet 1992; 339: 1249-53.

17.- McIntyre J, Gray G. What can we do to reduce mother to child transmission of HIV?. Br Med J 2002; 324: 218-21.

18.- Blanche S, Newell M L, Mayaux M J, Dunn D T, Teglas J P, Rouzioux C, et al. Morbidity and mortality in European children vertically infected by HIV-1: The French Pediatric HIV Infection Study Group and European Collaborative Study. J Acquir Immun Defic Syndr Hum Retrovirol 1997; 14: $442-50$.

19.- Resino S, Gurbindo M D, Bellón J M, Sánchez-Ramión S, Muñoz-Fernández M A. Predictive markers of clinical outcome in vertically HIV-1 infected infants, a prospective longitudinal study. Pediatr Res 2000; 47: 509-16.

20.- Manual Práctico de la Infección por VIH en el Niño. 2da. ed. Barcelona: Prous Science; 2000 .

21.- Grubman S, Gross E, Lerner-Weiss N, Hernández M, Mc Sherry G D, Hoytl L G, et al. Older children and adolescent living with perinatally acquired HIV. Pediatrics 1995; 95: 657-63.

22.- Abrams E J. Opportunist infections and other clinical manifestations of HIV disease in children. Pediatr Clin North Am 2000; 47: 79-108.

23.- Laufer M, Scott G B. Medical management of HIV disease in children. Pediatr Clin North Am 2000; 47: 127-53. 